\title{
A MODEL OF INTERACTION OF TRAVELERS, PARKING AGENCY AND AUTHORITIES FOR OPTIMIZATION FREE AND PAID PARKING
}

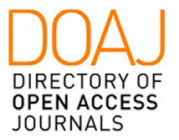

Crossref

\section{Mark Evgenyevich Koryagin}

Siberian Transport University,

Faculty Engineering Eco-

nomics, Novosibirsk, Russian

Federation

\section{Igor Vylegzhanin}

Siberian Transport University,

Faculty Engineering Eco-

nomics, Novosibirsk, Russian

Federation

Key words: parking behavior, parking policy, parking fee, parking space, urban transportation, land use planning, game theory

doi: $10.5937 /$ jaes0-28125

Cite article:

Koryagin, M. E., Vylegzhanin, I. (2021) A MODEL OF INTERACTION OF TRAVELERS, PARKING AGENCY AND AUTHORITIES FOR OPTIMIZATION FREE AND PAID PARKING, Journal of Applied Engineering Science, 19(3), 767-773, DOI:10.5937/jaes0-28125

Online aceess of full paper is available at: www.engineeringscience.rs/browse-issues 


\title{
A MODEL OF INTERACTION OF TRAVELERS, PARKING AGENCY AND AUTHORITIES FOR OPTIMIZATION FREE AND PAID PARKING
}

\author{
Mark Evgenyevich Koryagin*, Igor Vylegzhanin \\ Siberian Transport University, Faculty Engineering Economics, Novosibirsk, Russian Federation
}

The system of two parking lots is researched: paid and free. The task of the city authorities is to determine part of the land for parking agency. The agency selects the best parking fee, and travelers determine which parking to choose. The goals of each participant are different: passengers attempt to minimize the loss of time and parking fees, the agency maximizes profits, and the city thinks about the public good (in this case, about all travelers). The mutual dependence of participants leads to the need to apply game theory to describe their interaction. The mathematical model defines restrictions on the parameters for existence Nash equilibrium. The numerical example that does not contradict the existing picture of the world is considered.

Key words: parking behavior, parking policy, parking fee, parking space, urban transportation, land use planning, game theory

\section{INTRODUCTION}

The goal of many studies is to find models of sustainable urban development, in particular, models of sustainable traveler mobility. The main problem for a traveler is the choosing right strategy. The four-step urban planning process is comprised of the following [1]: trip generation, trip distribution, mode split, and traffic assignment. The main problem for a traveler also consists of similar steps. Therefore for the sustainable development government must reduce mobility, relieve the $\mathrm{CBD}$, and decrease car traffic $[2,3]$.

The traveler decisions at each stage are based on many factors. The most important problem for car user is the parking. The first question of the traveler: is parking spaces enough for free parking? The answer is negative in most big cities. The article [4] shows a sharp increasing in the cost of each additional parking space, so it is impossible to meet all the needs of travelers, especially in the CBD. Therefore the second question arises: what should be the cost of parking? The answer to these questions is provided by the parking policy, which is one of the main tools for travel demand management as a whole. At the same time, the answer to the first question lies in the field of land use, and the second in the field of transport systems. Such different fields of research are difficult to integrate into the overall model, since they use too different tools and indicators [5], but combination of the fields can significantly improve the efficiency of urban transportation systems.

One of the most effective ways to optimize the urban transport system is road pricing and parking pricing [6, 7]. But researchers have to describe the impact of the proposed solutions on travelers' behavior.

\section{Users' decision making}

More than half of the travelers prefer free on-street parking [8], so the violations control is required.

Most of the time [9] the car is parked at home $51 \%$, at the employer $20 \%$, on-street $3 \%$, illegally $9 \%$, off-street $9 \%$. Other work [8] shows a different ratio: $80 \%$ at home, $16 \%$ elsewhere, and only $4 \%$ of all time car is used. At the same time [10] the average parking time differs significantly depending the purpose of the trip: 8 hours at work, 1.5 hours shopping.

The traveler decision-making process has a hierarchical structure considering different factors [11]. At the same time, [12] it should be taken into account not only the rational behavior, but also the psychological characteristics of travelers on parking choice.

Mathematical models of travel behavior are quite complex, but some authors try to consider the issue comprehensively on the transport network, taking into account the travel route and parking choice simultaneously [6, 13].

For most authors the traveler has two alternatives: cruising for search of cheap (or free) parking or choose to pay [14-16]. The first alternative is usually on-street parking along the road, and the second option is off-street. It is noted that on-street parking has many disadvantages [17]: pollution, traffic jams, security, corruption, interference with pedestrians.

Most of authors consider the logit model [18-20] for a parking choice.

There is considered special cases of parking choice. The parking at the airport terminal and beyond [21] depends on the critical traveler time. The choice between two retailers significantly depends on the parking rates [22]. 
The research of different classes of users and parking spaces [11, 23] allows to examine more detailed various travelers and parking agencies behavior.

\section{Parking agencies}

Parking efficiency is determined by the percentage of places that are occupied. It is recommended [24] to find charges amount to achieve $85 \%$ parking occupancy. However, it is necessary to take into account the socio-economic situation [24] and the weak linear relationship between travelers' incomes and parking charges, which will help to determine the optimal parking size and its commercial prospects.

The relationship between business and government mainly consists of price restrictions, taxes and subsidies [25]. The parking taxes in the United States goes to the budget [26] and there lies between $6 \%$ and $31 \%$ of parking agencies revenue.

\section{Parking policy}

Three parking policy phases is suggested [27]:

phase one: the rise of parking regulation (free parking, applied when land is enough);

phase two: the advent of pricing parking;

phase three: parking policy as integral part of TDM strategies.

More effective parking spaces type [28] depends on the distance from the CBD. In the center it is underground and multi-level parking, the further away from the center it is the lower rate and more attractive ground parking.

The game theory is widely applied to parking management models. The simplest models are the competition between individual travelers [29-31]. In this model travelers choose optimal start time of the trip and parking lots. In $[15,32]$ the choice between private and public parking is researched.

In particular, the models of interaction between individual (atomic) travelers and the government [18, 29] is obtained, as well as between travelers as whole (continuum flow) and government are considered.

The competition between two parking agencies at the CBD [25] is considered, various game theoretic models are studied, including unregulated and regulated markets. The paper [33] considers the parking agencies price competition model as a non-cooperative two-stage following the leader model.

The competition between two parking agencies at the CBD [25] is considered, various game theoretic models are studied, including unregulated and regulated markets. The paper [33] considers the parking agencies price competition model as a non-cooperative two-stage following the leader model.

The paper [34] discusses various options of parking management: monopoly, oligopoly competition, and social optimum. A two-stage optimization model includes route and parking lots choice. The main conclusion of the paper is: the parking-and-ride $(P \& R)$ facility is unprofitable and should be subsidized in each market type. The government [35] does not need to regulate the rates for all private parking agencies it is enough to regulate only on-street parking rates. Travelers and private parking agencies react on government's policies, which will allow to achieving the greatest public good.

\section{Information technology}

The using of information technologies [36] allows to significantly reducing the parking lot search time by an order more when parking filling from 96 to $99 \%$. In [37] the information model allows to simulate the dynamic process includes random behavior of each traveler, which provides practical tools for the improving parking policy. Information systems for paid parking reservation help to avoid cruising [38].

\section{MATHEMATICAL STATEMENT OF THE PROBLEM}

Let's consider some destination for travelers object, such as an airport, retail, university, business center, etc. The model consists of free and paid parking zones. At the same time, free parking is located much further from the object than paid one. The total number of parking lots is assumed to be limited.

The main constant parameters of the model are $V$ - total number of free and paid parking lots;

$D_{1}$ - paid parking costs per parking lot (parking agency expenses);

$D$ - urban losses calculated for one free parking lot.

$\lambda$ - the intensity of car flow to the object,

$Y$ - the average value of time;

$t_{0}{ }^{0}$ - minimum search time in free parking,

$t_{1}^{0}$ - minimum search time in paid parking (includes payment processing),

$t_{0}{ }^{w}$ - walking time from free parking to the destination objectand back,

$t_{1}{ }^{w}$ - walking time from paid parking to destination object and back.

The variables are:

$V_{0}$ - number of free parking lots,

$V_{1}=V-V_{0}-$ number of paid parking lots,

$C^{p}$ - travel parking fee,

$p$ - the probability of paid parking choice.

\section{Parking time}

The parking search time depends on the parking capacity and occupancy. In fact, parking process looks like a queuing service with the flow of customers (cars) and service time (parking). Therefore, the queuing theory is best suited for describing parking service [7]. For a set of parking zones, this is already a queuing network [39]. 
However, the formulas for calculating the characteristics of multi-channel queuing systems (even Markov ones) are complicated, so parking times are usually described by the standard Bureau of Public Roads (BPR) model [6, 13, 40].

However, sometimes special models [41] which based on the parking search cruising are used.

All the ahead mentioned models show the average parking search time, and the time distribution satisfies the normal [23] law. In this paper, the BPR model is used for average parking search time too.

The average search time for a free parking space can be calculated using the formula

$t_{0}^{p}=t_{0}^{0}+\beta_{0} \cdot\left(\frac{\lambda(1-p)}{V_{0}}\right)^{\alpha_{0}}$

where $\alpha_{0}, \beta_{0}$ - calibration parameters.

Similarly, the average search time for a paid parking space can be calculated by the formula

$t_{1}^{p}=t_{1}^{0}+\beta_{1} \cdot\left(\frac{\lambda p}{V-V_{0}}\right)^{\alpha_{1}}$

where $\alpha_{1}, \beta_{1}$ - calibration parameters.

\section{The travelers' objective function}

Travelers' expenses must correspond to saving time and money. The travelers are not homogeneous, so the value of time is distributed by exponential law [42]. Therefore objective function can be set by the formula

$G(p)=\lambda\left((\lambda+\gamma p \ln p-\lambda p)\left(t_{0}^{p}+t_{0}^{w}\right)+C^{p} p+(\gamma p-\gamma p \ln p)\left(t_{1}^{p}+t_{1}^{w}\right)\right)=$

$=\lambda p C^{p}+\lambda \gamma(p \ln p-1)\left(t_{0}^{p}+t_{0}^{w}-t_{1}^{p}-t_{1}^{w}\right)+\lambda \gamma\left(t_{0}^{p}+t_{0}^{w}\right) \rightarrow \min$

Taking into account (1) and (2), it is transformed to:

$G^{\prime}(p)=\lambda y\left[\ln p\left(t_{0}^{p}+t_{0}^{w}-t_{1}^{p}-t_{1}^{w}\right)-p(\ln p-1)\left(\frac{\alpha_{1} \beta_{1}}{p}\left(\frac{\lambda p}{V-V_{0}}\right)^{\alpha_{1}}+\frac{\alpha_{0} \beta_{0}}{1-p}\left(\frac{\lambda(1-p)}{V_{0}}\right)^{\alpha_{0}}\right)\right]$.

$-\frac{\lambda \gamma \alpha_{0} \beta_{0}}{1-p}\left(\frac{\lambda(1-p)}{V_{0}}\right)^{\alpha_{0}}+\lambda C^{p}$

$G^{\prime}(p)=\lambda y\left[\ln p\left(t_{0}^{p}+t_{0}^{w}-t_{1}^{p}-t_{1}^{w}\right)-p(\ln p-1)\right.$

$\left.\cdot\left(\frac{\alpha_{1} \beta_{1}}{p}\left(\frac{\lambda p}{V-V_{0}}\right)^{\alpha_{1}}+\frac{\alpha_{0} \beta_{0}}{1-p}\left(\frac{\lambda(1-p)}{V_{0}}\right)^{\alpha_{0}}\right)\right]-\frac{\lambda \gamma \alpha_{0} \beta_{0}}{1-p}\left(\frac{\lambda(1-p)}{V_{0}}\right)^{\alpha_{0}}+\lambda C^{p}$

$G^{\prime}(p)=\lambda y\left[\operatorname{Inp}\left(t_{0}^{p}+t_{0}^{w}-t_{1}^{p}-t_{1}^{w}\right)-(p \ln p-p) \cdot\right.$

$\left.\cdot\left(\frac{\alpha_{1}\left(t_{1}^{p}-t_{1}^{0}\right)}{p}+\frac{\alpha_{0}\left(t_{0}^{p}-t_{0}^{0}\right)}{1-p}\right)\right]-\frac{\alpha_{0} \gamma \lambda\left(t_{0}^{0}-t_{0}^{0}\right)}{1-p}+\lambda C^{p}$

From (7) follows

$G^{\prime \prime}(p)=\lambda y\left[\frac{t_{0}^{p}+t_{0}^{w}-t_{1}^{p}-t_{1}^{w}}{p}-2 \ln p\left(\frac{\alpha_{1} \beta_{1}}{p}\left(\frac{\lambda p}{V-V_{0}}\right)^{\alpha_{1}}+\frac{\alpha_{0} \beta_{0}}{1-p}\left(\frac{\lambda(1-p)}{V_{0}}\right)^{\alpha_{0}}\right)\right]$

It is natural to assume that $t_{0}{ }^{p} \geq t_{1}{ }^{p}, t_{0}{ }^{w} \geq t_{1}{ }^{w}$, therefore, for any positive parameter values, the function $G(p)$ is convex downwards.

\section{The objective function of paid parking}

Solution of (5) is the probability of paid Parking choice

$p=e^{-\frac{C^{p}}{v\left(t_{0}^{p}+t_{0}^{w}-t_{1}^{p}-t_{1}^{w}\right)}}$

The objective function of parking agency (maximum profit) can be expressed as difference between income and expenses

$H\left(C^{p}\right)=\lambda p C^{p} \cdot e^{-\frac{C^{p}}{v\left(t_{0}^{p}+t_{0}^{w}-t_{1}^{p}-t_{1}^{w}\right)}}-D_{1} V_{1} \rightarrow \max$

The first derivative of the function $\mathrm{H}\left(\mathrm{C}^{\mathrm{p}}\right)$ is equal to

$H^{\prime}\left(C^{p}\right)=\lambda p\left(1-\frac{C^{p}}{v\left(t_{0}^{p}+t_{0}^{w}-t_{1}^{p}-t_{1}^{w}\right)}\right) \cdot e^{-\frac{C^{p}}{y\left(t_{0}^{p}+t_{1}^{w}-t_{1}^{p}-t_{1}^{w}\right)}}$

The maximum of the function is reached when the derivative is equal to zero

$\lambda p\left(1-\frac{C^{p}}{v\left(t_{0}^{p}+t_{0}^{w}-t_{1}^{p}-t_{1}^{w}\right)}\right) \cdot e^{-\frac{c^{p}}{y\left(t_{0}^{p}+t_{1}^{w}-t_{1}^{p}-t_{1}^{w}\right)}}=0$

Therefor optimal parking fee is

$C^{p}=\gamma\left(t_{0}^{p}+t_{0}^{w}-t_{1}^{p}-t_{1}^{w}\right)$

The second derivative of the objective function is equal to $H^{\prime \prime}\left(C^{p}\right)=-\frac{\lambda p}{V\left(t_{0}^{p}+t_{0}^{w}-t_{1}^{p}-t_{1}^{w}\right)}\left(2-\frac{C^{p}}{V\left(t_{0}^{p}+t_{0}^{w}-t_{1}^{p}-t_{0}^{w}\right)}\right) \cdot e^{-\frac{C^{p}}{V\left(t_{0}^{p}+t_{0}^{w}-t_{1}^{p}-t_{1}^{w}\right)}}$

That is, the target function is convex up at

$2-\frac{C^{p}}{V\left(t_{0}^{p}+t_{0}^{w}-t_{1}^{p}-t_{1}^{w}\right)} \geq 0\left(^{*}\right)$

\section{Socio-economic objective function of parking lots}

The objective function for free Parking from a socio-economic point of view is the sum of the traveler's time lost and the cost of Parking.

$F_{0}\left(t_{0}^{p}\right)=\lambda(\gamma+\gamma p \ln p-\gamma p)\left(t_{0}^{p}+t_{0}^{w}\right)+D V_{0} \rightarrow \min$

Using (1) the next formula is constructed

$F_{0}\left(t_{0}^{p}\right)=\lambda(\gamma+\gamma p \ln p-\gamma p)\left(t_{0}^{p}+t_{0}^{w}\right)+D \frac{\lambda(1-p)}{\sqrt[a_{0}]{\frac{t_{0}^{p}-t_{0}^{0}}{\beta_{0}}}} \rightarrow \min$

The same result is obtained for paid parking:

$F_{1}\left(t_{1}^{p}\right)=\lambda(y p-y p / n p-y p)\left(t_{1}^{p}+t_{i}^{w}\right)+D_{1}\left(V-V_{0}\right)+\lambda C^{p} p \rightarrow \min$

$F_{1}\left(t_{1}^{p}\right)=\lambda(\gamma p-\gamma p \ln p-\gamma p)\left(t_{1}^{p}+t_{i}^{w}\right)+\frac{D_{1} \lambda p}{\sqrt[a_{1}]{\frac{t_{1}^{p}-t_{1}^{0}}{\beta_{1}}}}+\lambda C^{p} p \rightarrow \min$ 
Total objective function is:

$F\left(t_{0}^{p}, t_{1}^{p}\right)=\lambda \gamma(p \ln p-p)\left(t_{0}^{p}+t_{0}^{w}-t_{1}^{p}-t_{1}^{w}\right)+D \lambda(1-p)\left(\frac{t_{0}^{p}-t_{0}^{0}}{\beta_{0}}\right)^{-\frac{1}{\alpha_{0}}}+$

$+D_{1} \lambda p\left(\frac{t_{1}^{p}-t_{1}^{0}}{\beta_{1}}\right)^{-\frac{1}{\alpha_{1}}}+\lambda p C^{p}$

At the same time, the variables $t_{0}^{p}$ and $t_{1}^{p}$ are not independent, they are related to each other by the relations arising from (1) and (2):

$t_{0}^{p}=t_{0}^{0}+\beta_{0}\left(\frac{V}{\lambda(1-p)}-\frac{p}{1-p}\left(\frac{t_{1}^{p}-t_{1}^{0}}{\beta_{1}}\right)^{-\frac{1}{\alpha_{1}}}\right)^{-\alpha_{0}}$

$t_{1}^{p}=t_{1}^{0}+\beta_{1}\left(\frac{V}{\lambda p}-\frac{1-p}{p}\left(\frac{t_{0}^{p}-t_{0}^{0}}{\beta_{0}}\right)^{-\frac{1}{\alpha_{0}}}\right)^{-\alpha_{1}}$

After replacing one variable the derivative of objective function is obtained

$\frac{d F}{d t_{0}^{p}}=\lambda \gamma+\lambda \gamma(p \ln p-p)\left(1+\frac{\beta_{1}(1-p)}{\alpha_{0} \alpha_{1} \beta_{0} p}\left(\frac{\lambda p}{V-V_{0}}\right)^{\alpha_{1}+1}\left(\frac{V_{0}}{\lambda(1-p)}\right)^{\alpha_{0}+1}\right)+$

$+\left(\frac{V_{0}}{\lambda(1-p)}\right)^{\alpha_{0}+1}\left(\frac{D_{1} \lambda(1-p)}{\alpha_{0} \alpha_{1}^{2} \beta_{0}}-\frac{D \lambda(1-p)}{\alpha_{0} \beta_{0}}\right)$

The sufficient condition on parameters for convexity downwards the function $F$ is obtained after some transformations

$V_{0}>V-\lambda p\left(\frac{D_{1}}{\alpha_{1} \beta_{1} V(1-\ln p)}\right)^{-\frac{1}{\alpha_{1}+1}}$

\section{Nash equilibrium}

In this problem statement, it is sufficient to find the values of the unknowns $C^{p}, p, V_{0}$ as the coordinates of the Nash equilibrium point. To do this, it is enough to solve the system.

$\left\{\begin{array}{l}H^{\prime}\left(C^{p}\right)=0 \\ G^{\prime}(p)=0 \text { under conditions (1) and (2). } \\ F^{\prime}\left(t_{0}^{p}\right)=0\end{array}\right.$

If the solution of the system meets the conditions $\left({ }^{*}\right)$ and (25), it will be the solution of the problem.

Unknowns $t_{0}{ }^{p} t_{1}{ }^{p}$ can be found after solving the system using formulas (2) and (1).

The system has a solution due to the corresponding convexity of the objective functions.

The system consists of conditions (4), (8), and a condition equal to zero (24). Excluding the unknown $C^{p}$ from the system, the last system is constructed.

$(\ln p+1)\left(\beta_{0}\left(\frac{\lambda(1-p)}{V_{0}}\right)^{\alpha_{0}}-\beta_{1}\left(\frac{\lambda p}{V-V_{0}}\right)^{\alpha_{1}}+t_{0}^{0}+t_{0}^{w}-t_{1}^{0}-t_{1}^{w}\right)-(p / n p-p+1)$.

$\left\{\cdot \frac{\alpha_{0} \beta_{0}}{1-p}\left(\frac{\lambda(1-p)}{V_{0}}\right)^{\alpha_{0}}-(\operatorname{In} p-1) \cdot \alpha_{1} \beta_{1}\left(\frac{\lambda p}{V-V_{0}}\right)^{\alpha_{1}}=0\right.$

$V+\gamma(\operatorname{In} p-1)\left(p+\frac{\beta_{1}(1-p)}{\alpha_{0} \alpha_{1} \beta_{0}}\left(\frac{\lambda p}{V-V_{0}}\right)^{\alpha_{1}+1}\left(\frac{V_{0}}{\lambda(1-p)}\right)\right)+\frac{(1-p)\left(D_{1}-\alpha_{1}^{2} D\right)}{\alpha_{0} \alpha_{1}^{2} \beta_{0}}\left(\frac{V_{0}}{\lambda(1-p)}\right)^{\alpha_{0}+1}=0$

\section{RESULTS}

Let's consider a numerical example with the following parameters: $\alpha_{0}=5, \alpha_{1}=1, \beta_{0}=\beta_{1}=0.03, \lambda=1000, D=5, D_{1}=15$, $V=1000, t_{0}^{0}=0.2, t_{0}{ }^{w}=0.1, t_{1}^{0}=0.02, t_{1}{ }^{w}=0.02$.

There is noted the difference between the BPR model parameters for paid and free parking. The increasing in the number of filled lots makes the traveler cruising around the on-street parking lots, so the degree is equal to $\alpha_{0}=5$. For paid parking, the free space can be shown by information systems or parking attendant, so the distance to the nearest parking lot will slowly increase when the parking lot is filling $\left(\alpha_{1}=1\right)$.

The sensitivity of parking time for the proposed mathematical model is researched. First of all, let's consider the influence of the value of time (VOT).

It is obvious that the increasing in the VOT (Fig. 1) leads to increasing the probability of paid parking using, which in turn increases the efficiency of the agency. Therefore, if standard of living is increasing then free parking needs more time and paid parking less one.

The increase in the intensity of travelers' flow (Fig. 2) may be associated with the growth of the city's population or with the increasing in the level of motorization, which is typical for developing countries. This leads to decreasing in the number of available parking lots, which increases parking time. The increasing percentage is the same, but the benefit from paid parking increases from 9 to 15 minutes.

The parking spaces increasing (Fig. 3) is not always possible, but it provides significant parking time savings for travelers. However, most cities are experiencing the reverse process of reducing the number of parking spaces.

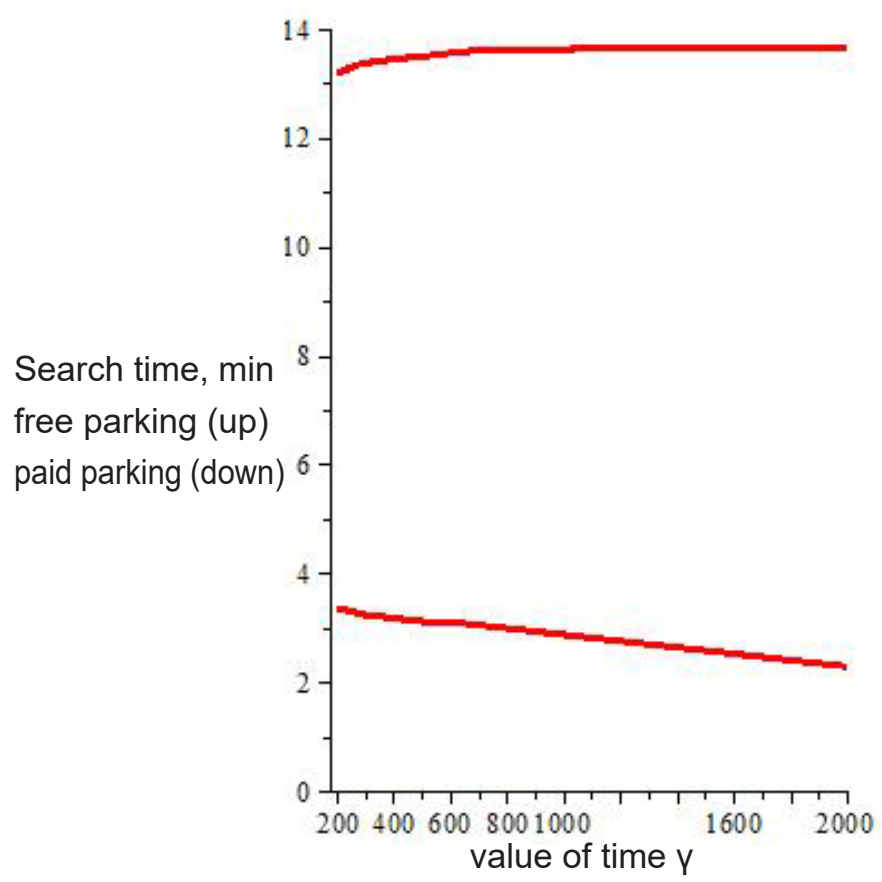

Figure 1: The influence of VOT on search time 


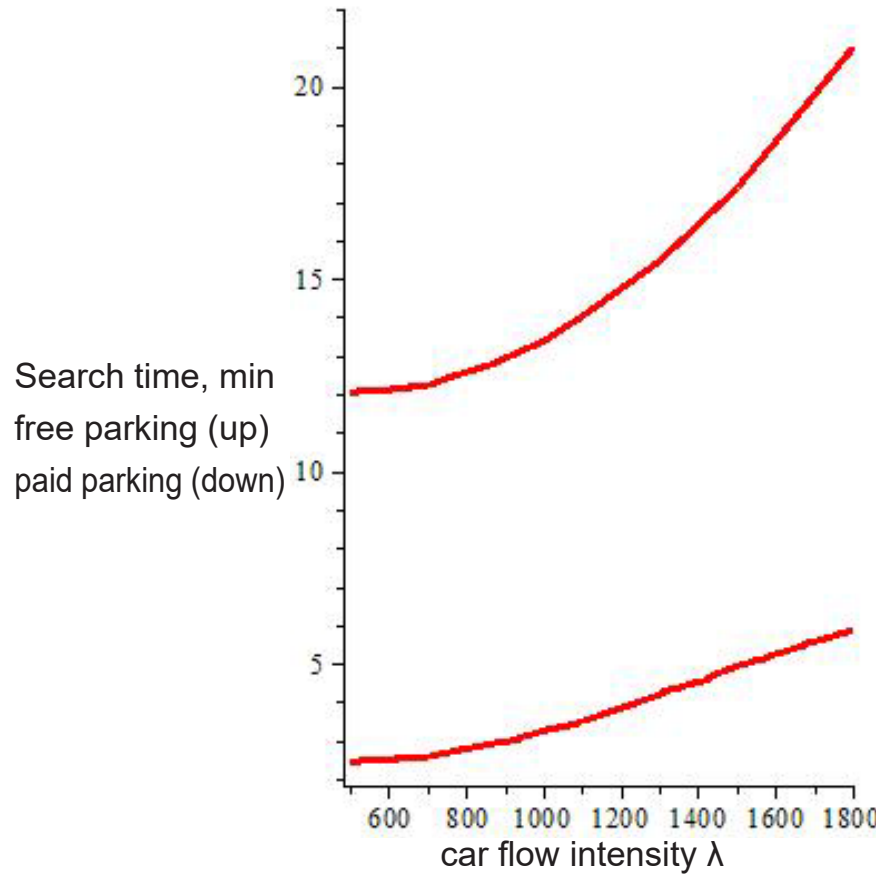

Figure 2: The influence of car flow intensity on search time

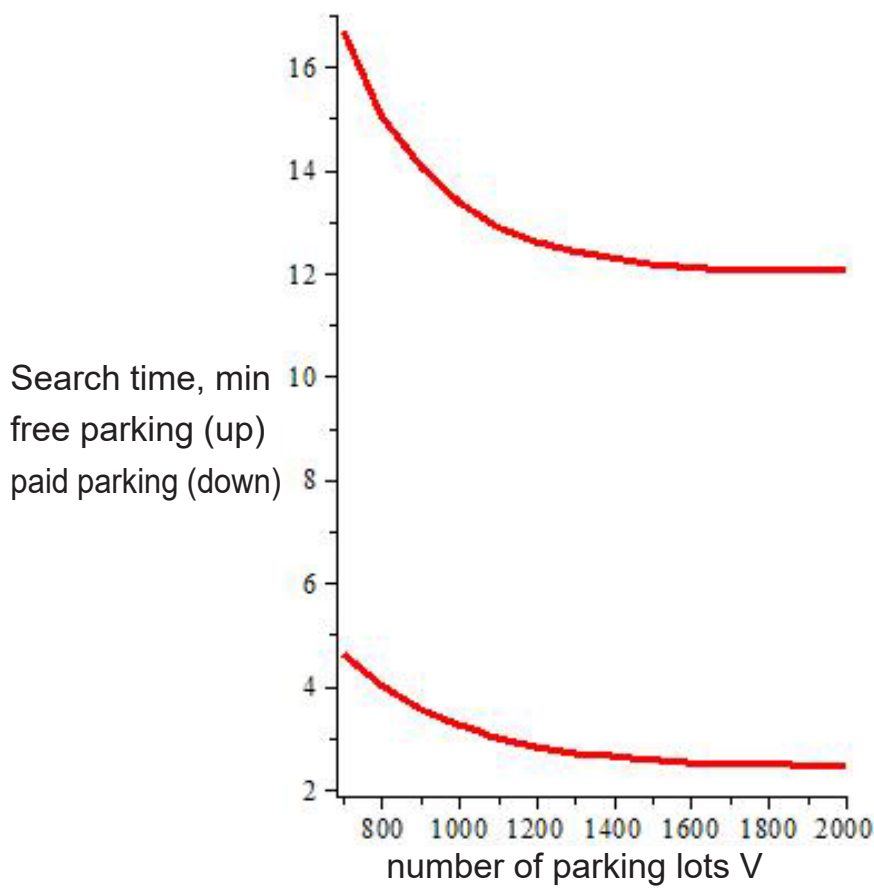

Figure 3: The influence of number of parking lots on search time

\section{CONCLUSION}

The proposed mathematical model explores a system of two parking lots types: paid and free. The parking time is set using the BPR function, which depends on the capacity of the parking space. At the same time, free parking is located much further from the object than paid one.

Travelers' expenses must correspond to saving time and money. The travelers are not homogeneous, so the value of time is distributed by exponential law. The traveler objective function consists of weighed loss of time when using free parking, loss of money and time when using paid parking. The traveler strategy is the probability of paid parking choice.

The parking agency objective function is the maximum profit. The agency strategy is the travel parking fee. The city authorities objective function is the sum of the traveler's time lost and the cost of parking. The authorities strategy is the search time for free parking lots, which depends of number of free parking lots.

The task of the city authorities is to determine the part of the lots for the parking of the agency. The agency chooses the optimal parking fee, and travelers decide which parking to choose. The goals and strategies of each participant are different. Therefore, to solve conflicts of interest, a game-theoretic mathematical model has been constructed. The existence of the Nash equilibrium is proved for this model.

A numerical example shows how the parameters of the transport process affect to the time for paid and free parking. In particular, the increasing of VOT leads to decreasing in the time of paid parking and an increasing time for free parking, i.e. city authorities policy encourages the use of paid parking.

It is impossible to reduce parking time when traffic flow is increasing. However, the time difference between the two types of parking is increasing.

The increasing in the number of parking lots leads to decreasing in parking time, especially for free parking. However, the opposite process is often observed. Therefore, when parking spaces is decreasing, it becomes disadvantageously to use free parking.

The considered numerical example doesn't conflict with the whole scheme of things. Therefor, the proposed mathematical model will develop. Several areas for future research are suggested below:

increase the number of parking agencies;

increase the number of travelers' flows;

accounting the travel mode and rout choice;

scaling up to the level of many districts of the city; integration with public transport.

The research will eventually allow to finding an optimal strategy for the development of the city's transport system as a whole, in order to make the city's life sustainable and socially-oriented.

\section{REFERENCES}

1. Pendyala, R. M., Kitamura, R., \& Reddy, D. P. (1998). Application of an activity-based travel-demand model incorporating a rule-based algorithm. Environment and Planning B: Planning and Design, vol. 25, № 5, 753-772, DOI: 10.1068/b250753

2. Vuchic, V. R. (1999). Transportation for livable cities. Center for urban policy research press, Rutgers University, Brunswick, N.J. 
3. Gärling, T., \& Schuitema, G. (2007). Travel demand management targeting reduced private car use: effectiveness, public acceptability and political feasibility. Journal of Social Issues, vol. 63, № 1, 139-153, DOI:10.1111/j.1540-4560.2007.00500.x

4. Shoup, D. C. (1997). The high cost of free parking. Journal of planning education and research, vol. 17, № 1, 3-20, DOI:10.1177/0739456X9701700102

5. Te Brömmelstroet, M., Bertolini, L. (2008). Developing land use and transport PSS: meaningful information through a dialogue between modelers and planners. Transport policy, vol. 15, № 4, 251-259, DOI:10.1016/j.tranpol.2008.06.001

6. Balijepalli, N.C., Shepherd, S.P., May, A.D. (2008). Modelling the Choice of Car Parks in Urban Areas and Managing the Demand for Parking. 87th Annual Meeting of the Transportation Research Board.

7. Larson, R. C., Sasanuma, K. (2010). Urban Vehicle Congestion Pricing: A Review. Journal of Industrial and Systems Engineering, vol. 3, № 4, 227-242.

8. Marsden, G.R. (2014). Parking Policy. Ison S. Parking Issues and Policies. Transport and Sustainability, Emerald Group Publishing Limited, 11 - 32, DOI:10.1108/S2044-994120140000005016

9. Zhang, X., Huang, H. J., \& Zhang, H. M. (2008). Integrated daily commuting patterns and optimal road tolls and parking fees in a linear city. Transportation Research Part B: Methodological, vol. 42, № 1, 3856, DOI:10.1016/j.trb.2007.06.001

10. Bates, J., Leibling, D. (2012). Spaced Out, Perspectives on parking policy, RAC Foundation, London.

11. Lam, W. H., Li, Z. C., Huang, H. J., \& Wong, S. C. (2006) Modeling time-dependent travel choice problems in road networks with multiple user classes and multiple parking facilities. Transportation Research Part B: Methodological, vol. 40, № 5, 368-395, DOI:10.1016/j.trb.2005.05.003

12. Guo, L., Huang, S., Zhuang, J., \& Sadek, A. W. (2013). Modeling parking behavior under uncertainty: a static game theoretic versus a sequential neo-additive capacity modeling approach. Networks and Spatial Economics, vol. 13, № 3, 327-350.

13. van Nieuwkoop, R. H., Axhausen, K. W., \& Rutherford, T. F. (2016). A traffic equilibrium model with paid-parking search. Journal of Transport Economics and Policy (JTEP), vol. 50, № 3, 262-286.

14. Shoup, D. C. (2006). Cruising for parking. Transport Policy, vol. 13, № 6, 479-486, DOl:10.1016/j.tranpol.2006.05.005
15. Calthrop, E., \& Proost, S. (2006). Regulating onstreet parking. Regional Science and Urban Economics, vol. 36, № 1, 29-48, DOI:10.1016/j.regsciurbeco.2005.04.002

16. Zheng, N., Geroliminis, N. (2016). Modeling and optimization of multimodal urban networks with limited parking and dynamic pricing. Transportation Research Part B: Methodological, vol. 483, 36-58, DOI:10.1016/j.trb.2015.10.008

17. Rye, T. (2010). Parking management: a contribution towards liveable cities, Module 2c (Sustainable transport: a sourcebook for policy-makers in developing cities). Eschborn, Germany.

18. Hollander, Y., Prashker, J. N., \& Mahalel, D. (2006). Determining the desired amount of parking using game theory. Journal of urban planning and development, vol. 132, № 1, 53-61, DOI:10.1061/ (ASCE)0733-9488(2006)132:1(53)

19. Millard-Ball, A., Weinberger, R. R., \& Hampshire, R. C. (2014). Is the curb $80 \%$ full or $20 \%$ empty? Assessing the impacts of San Francisco's parking pricing experiment. Transportation Research Part A: Policy and Practice, vol. 63, 76-92, DOI:10.1016/j. tra.2014.02.016

20. Bagloee, S. A., Asadi, M., \& Richardson, L. (2012). Methodology for parking modeling and pricing in traffic impact studies. Transportation research record, vol. 2319, № 1, 1-12, DOI:10.3141/2319-01

21. Hsu, C. I., \& Lin, F. S. (1997). Demand distribution and operating strategies of airport remote and terminal parking facilities. Transportation Planning and Technology, vol. 20, № 3, 219-234 DOI:10.1080/03081069708717590

22. De Borger, B., \& Russo, A. (2017). The political economy of pricing car access to downtown commercial districts. Transportation Research Part B: Methodological, vol. 98, 76-93, DOI:10.1016/j. trb.2016.12.012

23. Zhao, C., Li, S., Wang, W., Li, X., \& Du, Y. (2018). Advanced Parking Space Management Strategy Design: An Agent-Based Simulation Optimization Approach. Transportation Research Record, vol. 2672, № 8, 901-910, DOI:10.1177/0361198118758671

24. Litman, T. (2018). Parking pricing implementation guidelines. Victoria transport policy institute. Victoria, British Columbia. 
25. Qian, Z. S., Xiao, F. E., \& Zhang, H. M. (2011). The economics of parking provision for the morning commute. Procedia-Social and Behavioral Sciences, vol. 17, 612-633, DOI:10.1016/j.sbspro.2011.04.535

26. Litman, T. A. (2006). Parking taxes: evaluating options and impacts. Victoria transport policy institute. Victoria, British Columbia.

27. Mingardo, G., Van Wee, B., \& Rye, T. (2015). Urban parking policy in Europe: A conceptualization of past and possible future trends. Transportation Research Part A: Policy and Practice, vol. 74, 268-281, DOI:10.1016/j.tra.2015.02.005

28. Brueckner, J. K., \& Franco, S. F. (2017). Parking and urban form. Journal of Economic Geography, vol. 17, № 1, 95-127, DOI:10.1093/jeg/lbv048

29. Zong, F., He, Y., \& Yuan, Y. (2015). Dependence of parking pricing on land use and time of day. Sustainability, vol. 7, № 7, 9587-9607, DOI:10.3390/ su7079587

30. Takayama, Y., \& Kuwahara, M. (2016). Scheduling preferences, parking competition, and bottleneck congestion: A model of trip timing and parking location choices by heterogeneous commuters. MPRA Paper 68938, University Library of Munich, Germany.

31. He, F., Yin, Y., Chen, Z., \& Zhou, J. (2015). Pricing of parking games with atomic players. Transportation Research Part B: Methodological, vol. 73, 1-12, DOI:10.1016/j.trb.2014.12.003

32. Kokolaki, E., Karaliopoulos, M., \& Stavrakakis, I. (2012). Leveraging information in vehicular parking games. arXiv preprint arXiv:1207.5747.

33. Mackowski, D., Bai, Y., \& Ouyang, Y. (2015). Parking space management via dynamic performance-based pricing. Transportation Research Part C: Emerging Technologies, vol. 59, 66-91, DOI:10.1016/j. trc.2015.05.021

34. Wenbo, F., \& Khan, M. B. (2012). Modeling the parking pricing of multiple parking facilities under different operation regimes. Journal of Transportation Technologies, vol. 2, № 3, 260, DOI:dx.doi.org/10.4236/ jtts.2012.23028

35. Inci, E., \& Lindsey, R. (2015). Garage and curbside parking competition with search congestion. Regional Science and Urban Economics, vol. 54, 49-59, DOI:10.1016/j.regsciurbeco.2015.07.003

36. Arnott, R. (2014). On the optimal target curbside parking occupancy rate. Economics of Transportation, vol. 3, № 2, 133-144, DOI:10.1016/j. ecotra.2014.07.001

37. Benenson, I., Martens, K., \& Birfir, S. (2008). PARKAGENT: An agent-based model of parking in the city. Computers, Environment and Urban Systems, vol. 32, № 6, 431-439, DOI:10.1016/j.compenvurbsys.2008.09.011
38. Tsai, M. T., \& Chu, C. P. (2012). Evaluating parking reservation policy in urban areas: An environmental perspective. Transportation Research Part D: Transport and Environment, vol. 17, № 2, 272-272, DOI:10.1016/j.trd.2011.10.006

39. Dowling, C., Fiez, T., Ratliff, L., \& Zhang, B. (2018). How Much Traffic is Searching for Parking? Simulating Curbside Parking as a Network of Finite Capacity Queues. arXiv preprint arXiv:1702.06156.

40. Balijepalli, N. C., Shepherd, S. P., \& Kant, P. (2015). Calibration and validation of parking search-time function. Proceedings of the Institution of Civil Engineers-Transport, Thomas Telford Ltd, vol. 168, № 1, 3-14.

41. Arnott, R., Inci, E., \& Rowse, J. (2015). Downtown curbside parking capacity. Journal of Urban Economics, vol. 86, 83-97, DOI:10.1016/j.jue.2014.12.005

42. Koryagin, M. E. (2008). Competition of public transport flows. Automation and Remote Control, vol. 69, № 8, 1380-1389, DOI:10.1134/S0005117908080109
Paper submitted: 25.08.2020.

Paper accepted: 12.02.2021.

This is an open access article distributed under the CC BY 4.0 terms and conditions. 